\title{
ANALISIS KEUNTUNGAN USAHA TAPE SUCIPTO DI KELURAHAN KLEAK KOTA MANADO
}

\author{
Nyariang Belen \\ Martha Mareyke Sendow \\ Sherly Gladys Jocom
}

\begin{tabular}{ll}
\hline Naskah diterima melalui Website Jurnal Ilmiah agrisosioekonomi@unsrat.ac.id & : Selasa, 14 Januari 2020 \\
Disetujui diterbitkan & $:$ Selasa, 21 Januari 2020 \\
\hline
\end{tabular}

\begin{abstract}
The purpose of this study was to analyze how much profit from the Sucipto Tape business in Kelurahan Kleak, Manado City. The study was conducted in Kelurahan Kleak Lingkungan 4, Malalayang District, Manado City. This research was conducted for 3 months starting in September 2019 until November 2019. Primary data were collected by direct interview with the owner of the Sucipto Tape business. Data collected in the form of data on the selling price of tape products, production of tape produced in one month of production, production costs involve fixed costs (electricity costs and depreciation costs) and variable costs (transportation costs, costs of main raw materials, costs of supporting materials, fuel costs, packaging costs, labor costs). The data collected was then analyzed using Profit Analysis and Revenue Cost Ratio Analysis. The results showed that the Sucipto tape business in the Kleak Kelurahan of Manado City earned a monthly profit of Rp. 1.990.332,33. The R / C value of the Sucipto Tape Business in September 2019 of 1.52 shows a number> 1 , so it can be concluded that this business was profitable. ${ }^{*}{ }^{e p r m}{ }^{*}$
\end{abstract}

Keywords: tape business, profit, $R$ / C ratio, Kleak Urban Village

\section{ABSTRAK}

Tujuan penelitian ini untuk menganalisis berapa besar keuntungan dari usaha Tape Sucipto di Kelurahan Kleak Kota Manado. Penelitian dilaksanakan di Kelurahan Kleak Lingkungan 4 Kecamatan Malalayang Kota Manado. Penelitian ini dilakukan selama 3 bulan mulai bulan September 2019 sampai bulan November 2019. Data yang akan digunakan dalam penelitian ini adalah data primer dan sekunder. Data primer dikumpulkan dengan cara wawancara langsung dengan pemillik usaha Tape Sucipto. Data yang dikumpulkan berupa data Harga jual produk tape, Produksi tape yang dihasilkan dalam satu bulan produksi, biaya produksi menyangkut biaya tetap (biaya listrik dan biaya penyusutan) dan biaya variabel (biaya transportasi, biaya bahan baku utama, biaya bahan penolong, biaya bahan bakar, biaya pengemasan, biaya tenaga kerja). Data yang dikumpulkan kemudian dianalisis menggunakan analisis keuntungan dan Analisis Revenue Cost Ratio. Hasil penelitian menunjukkan bahwa usaha tape Sucipto di Kelurahan Kleak Kota Manado memperoleh keuntungan setiap bulannya sebesar Rp. 1.990.332,33. Nilai R/C Usaha Tape Sucipto pada bulan September 2019 sebesar Rp.1,52 menunjukkan angka >1, maka dapat disimpulkan bahwa usaha ini menguntungkan. ${ }^{* e p r m *}$

Kata Kunci: Usaha Tape, Keuntungan, R/C ratio, Kelurahan Kleak

Agrisosioekonomi:

Jurnal Transdisiplin Pertanian (Budidaya Tanaman, Perkebunan, Kehutanan, Peternakan, Perikanan), Sosial dan Ekonomi 


\section{PENDAHULUAN}

\section{Latar Belakang}

Sektor pertanian merupakan sektor utama dalam perekonomian negara Indonesia atau bisa disebut sebagai negara agraris karena sebagian besar penduduk Indonesia menjadikan sektor pertanian sebagai sumber kehidupan. Pembangunan ekonomi menitikberatkan pada bidang pertanian dan industri yang berbasis pertanian atau biasa disebut sebagai agroindustri.

Di Indonesia Singkong atau ubi kayu mempunyai arti ekonomi penting dibandingkan dengan umbi-umbi lainnya. Jenis ini kaya akan karbohidrat dan merupakan makanan pokok di daerah tandus di Indonesia yaitu Umbinya digunakan sebagai pangan olahan.

Salah satu hasil olahan yang menggunakan ubinya sebagai bahan baku adalah Tape. Tape sangat diminati oleh masyarakat diberbagai daerah terutama khususnya masyarakat Jawa dan juga harganya sangat terjangkau.

CV Cipta Panca Persada masih tergolong sebagai industri rumah tangga. Industri rumah tangga ini mengelolah 3 macam produk yaitu terdiri dari tempe, tahu, dan tape. Tahu dan tempe merupakan produk utama sedangkan produk tape hanya merupakan produk pelengkap dalam $\mathrm{CV}$ Cipta Panca Persada dan disetiap produk tersebut diberi nama lebel "Sucipto". Lokasi industri ini berada di Kelurahan Kleak Kota Manado.

Usaha industri ini merupakan usaha yang sudah berdiri cukup lama dan telah beroperasi sejak tahun 1988 sampai dengan saat ini. Pemilik industri rumah tangga ini yaitu ibu Sunarmi, berumur 68 tahun. Alasan diberi nama lebel "sucipto" adalah karena pada saat melakukan kerja sama dengan super market ibu Sunarmi harus menamai produk yang akan dijual, dan tanpa berpikir panjang ibu Sunarmi memberikan nama produk penjualannya atas nama "sucipto" dimana sucipto itu adalah nama suami ibu Sunarmi. Sehingga bisa didistribusikan ke beberapa super market - super market yang ada di kota Manado. Usaha yang telah bertahuntahun berjalan ini relatif stabil karena, harganya bisa dijangkau dan juga sudah banyak peminat atau pembeli tetap akan tetapi sebagian besar produksi Tape ini masih memiliki keterbatasan pelanggan karena masih banyak masyarakat di kota Manado belum semua mengenal tentang produk tape dan juga adanya tenaga kerja yang mengerjakan produk tape ini hanya satu orang yang berasal dari keluarga itu sendiri sehingga setiap hari dalam satu kali memproduksi banyaknya Tape masih relatif sama padahal permintaan dari pasar banyak.

Tujuan dari meneliti yaitu untuk mengkaji mengenai berapa besar keuntungan yang diperoleh dari usaha tape tersebut.

\section{Industri Rumah Tangga}

Industri didasarkan pada banyaknya tenaga kerja dibedakan menjadi 4 golongan yaitu:

a. Industri besar memiliki jumlah tenaga kerja 100 orang atau lebih.

b. Industri sedang memiliki jumlah tenaga kerja antara 20-99 orang.

c. Industri kecil memiliki jumlah tenaga kerja antara 5-19 orang.

d. Industri rumah tangga memiliki jumlah tenaga kerja 1-4 orang.

Industri rumah tangga merupakan salah satu bagian dari usaha kecil yang kegiatan usaha maupun produksinya dikelola rumah tangga.

Biaya Produksi atau Production Cost dapat diartikan sebagai total biaya yang harus dikeluarkan untuk sumber daya yang digunakan untuk memproduksi barang atau jasa untuk dijual kepada pelanggan.

\section{Penerimaan}

Penerimaan merupakan hasil penjualan dari jumlah barang yang terjual. Semakin banyak barang yang diproduksi dan terjual, maka semakin besar pula penerimaan.

Menurut Boediono (2016) total penerimaan merupakan penerimaan total produsen dari hasil penjualan outputnya. Rumus penerimaan bisa dituliskan seperti ini: $\mathrm{TR}=\mathrm{Q} \times \mathrm{P}_{\mathrm{Q}}$

\section{Keuntungan}

Menurut Kumalasari (2016), keuntungan dari suatu usaha tergantung pada hubungan antara biaya produksi yang dikeluarkan dengan jumlah penerimaan dari hasil penjualan, dengan pusat perhatian ditunjukan bagaimana cara menekan biaya sewajarnya supaya dapat memperolah keuntungan sesuai dengan yang diinginkan. Adapun biaya yang dikeluarkan adalah biaya tetap dan biaya variabel. 
Keuntungan dapat dihitung dengan rumus:

\section{$\pi=$ TR-TC}

Dimana:

$\pi \quad=$ Keuntungan(profit)

$\mathrm{TR}=$ Penerimaan Total

$\mathrm{TC}=$ Biaya Total, yaitu semua biaya yang dikeluarkan untuk menghasilkan suatu barang (Soeharni, 2006).

\section{Rumusan Masalah}

Berdasarkan latar belakang yang telah dikemukakan, maka yang menjadi permasalahan dalam penelitian ini adalah berapa besar keuntungan dari usaha Tape Sucipto Di Kelurahan Kleak Kota Manado?

\section{Tujuan}

Tujuan penelitian adalah untuk menganalisis keuntungan dari usaha Tape Sucipto di Kelurahan Kleak Kota Manado.

\section{Manfaat Penelitian}

Penelitian ini bermanfaat untuk:

1. Bagi peneliti, penelitian ini sebagai salah satu karya ilmiah untuk mengembangkan pengetahuan dan wawasan mengenai industri rumah tangga Tape.

2. Bagi pihak Tape Sucipto, dapat menjadi bahan masukan yang bermanfaat untuk meningkatkan keuntungan dalam berusaha.

3. Bagi pihak lain, diharapkan dapat menambahkan wawasan dan pengetahuan serta dapat dijadikan acuan dan informasi untuk penelitian selanjutnya.

\section{METODE PENELITIAN}

\section{Waktu dan Tempat Penelitian}

Penelitian ini dilakukan selama 3 bulan mulai dari tahap persiapan hingga penyusunan laporan yakni di mulai bulan September 2019 sampai bulan November 2019. Penelitian dilaksanakan di Kelurahan Kleak Lingkungan 4 Kecamatan Malalayang Kota Manado.

\section{Teknik Pengumpulan Data}

Data yang akan digunakan dalam penelitian ini adalah data primer. data primer merupakan data yang diperoleh peneliti di lapangan langsung dari sumbernya yaitu dalam penelitian ini adalah pemillik usaha Tape Sucipto.

\section{1) Harga $(\mathbf{R p})$}

\section{Konsep Pengukuran Variabel}

Yaitu harga jual produk tape yang dihasilkan sesuai dengan ukuran yang ada.

\section{2) Produksi (Bungkus)}

Yaitu jumlah produksi tape yang dihasilkan dalam satu bulan produksi.

3) Biaya Produksi (Rp)

Yaitu besar biaya yang dikeluarkan dalam pembuatan tape setiap kali produksi perbulan yang terdiri dari:

a. Biaya Tetap

- Biaya Listrik (Rp)

Biaya yang dikeluarkan untuk membayar listrik perbulan

- Biaya Penyusutan Alat (Rp)

Menurut Kuswadi (2006) dalam

Wardani (2008) untuk menghitung besar biaya penyusutan peralatan dengan menggunakan metode garis lurus dengan rumus sebagai berikut:

\section{Biaya Penylusutan Alat $=\frac{\text { Nilai Investasi Awal }- \text { Nilai Investasi Akhir }}{\text { Umur Ekonomis(bulan) }}$}

b. Biaya Variabel

- Biaya Transportasi (Rp)

Biaya perbulan yang digunakan untuk memasarkan tape diluar tempat usaha.

- Biaya Bahan Baku (Rp)

Bahan baku utama yaitu singkong yang dipakai dalam proses produksi perbulan.

- Biaya Bahan Penolong (Rp)

Bahan penolong yang digunakan adalah ragi dalam proses produksi perbulan.

- Biaya Bahan Bakar (Rp)

Biaya perbulan yang digunakan untuk membeli bahan bakar yaitu Gas Lpg. 
- Biaya Pengemasan (Rp)

Terdiri dari biaya plastic kemasan dalam satu bulan.

- Biaya Tenaga Kerja (Rp)

Upah tenaga kerja yang dibayarkan perbulan

c. Biaya Total (Rp)

Biaya tetap ditambah biaya variabel dalam satu bulan.

\section{4) Penerimaan (Rp)}

Jumlah produksi dalam satu bulan dikalikan dengan harga yang berlaku.

\section{5) Keuntungan (Rp)}

Selisih antara jumlah penerimaan dalam satu bulan dan biaya total yang dikeluarkan dalam satu bulan.

\section{Metode Analisis Data}

Data yang dikumpulkan kemudian akan dianalisis menggunakan analisis keuntungan yaitu dengan menghitung selisih antara penerimaan dengan biaya yang digunakan kemudian di lanjutkan dengan rumus Analisis Revenue Cost Ratio. Untuk mengukur keuntungan digunakan rumus sebagai berikut:

$$
\begin{aligned}
& \pi=\mathrm{TR}-\mathrm{TC} \\
& \mathrm{TR}=\mathrm{Q} \times \mathrm{P}_{\mathrm{Q}} \\
& \mathrm{TC}=\mathrm{TFC}+\mathrm{TVC}
\end{aligned}
$$

Kemudian untuk mengetahui apakah usaha Tape Sucipto meguntungkan atau tidak digunakan rumus:

$$
\begin{aligned}
\mathrm{a} & =\mathrm{R} / \mathrm{C} \\
& =\{(\mathrm{Py} \cdot \mathrm{Y}) /(\mathrm{FC}+\mathrm{VC})\}
\end{aligned}
$$

Apabila:

$\mathrm{R} / \mathrm{C}<1$, berarti usaha mengalami kerugian

$\mathrm{R} / \mathrm{C}=1$, berarti usaha tidak menguntungkan dan tidak merugikan

$\mathrm{R} / \mathrm{C}>1$, berarti usaha tape menerima keuntungan.

\section{HASIL DAN PEMBAHASAN}

\section{Deskripsi Umum Usaha Tape CV Cipta Panca Persada}

Lokasi industri CV Cipta Panca Persada ini berada di Kelurahan Kleak Kota Manado. Sebelah utara berbatasan dengan Kecamatan Sario, sebelah Timur dan Selatan berbatasan dengan Kecamatan Pineleng, sebelah Barat berbatasan dengan Laut Manado.
Industri ini tergolong industri rumah tangga. Industri ini memiliki 3 macam produk yaitu Tempe, Tahu dan Tape. Tempe dan Tahu merupakan produk utama dalam usaha ini sedangkan Tape hanya merupakan produk pelengkap dengan tujuan menambah variasi produk. Industri rumah tangga ini mengolah ubi kayu menjadi tape dengan jumlah tenaga kerja satu orang yang berasal dari keluarga itu sendiri. Jumlah produksi tape yang dihasilkan terbilang masih sedikit dan juga tenaga kerja masih berasal dari keluarga itu sendiri.

Usaha industri ini merupakan usaha yang sudah berdiri cukup lama dan telah beroperasi sejak tahun 1988 sampai dengan saat ini. Pemilik industri rumah tangga ini yaitu ibu Sunarmi, berumur 68 tahun. Alasan diberi nama tape "sucipto" adalah karena pada saat melakukan kerja sama dengan supermarket ibu Sunarmi harus menamai produk yang akan dijual, dan tanpa berpikir panjang Ibu Sunarmi memberikan nama produk penjualannya atas nama "Sucipto" dimana Sucipto itu adalah nama suami Ibu Sunarmi.

Proses pembuatan tape dilakukan setiap seminggu dua kali, dalam satu kali produksi membutuhkan 1 karung ubi kayu dan menghasilkan 120 bungkus produk tape "Sucipto" dengan berat bersih 250 gr dengan harga Rp.6.000/bungkus.

Target pasar dari industri ini adalah super market-super market yang ada di kota Manado seperti: Golden, Lotte, Indogrosir, Rumah Makan KMB, dan Takadeli Roti.

\section{Proses Produksi Tape}

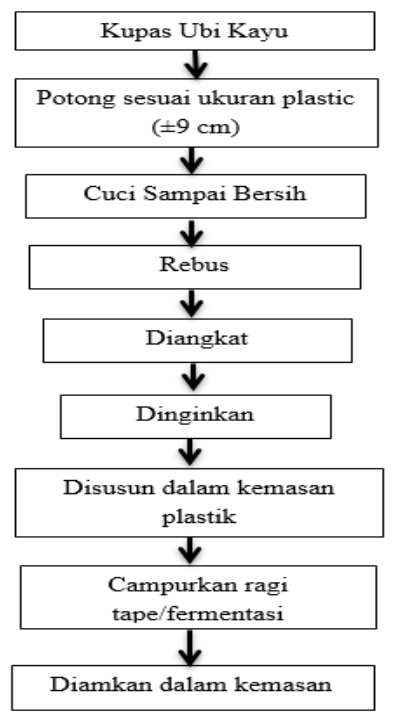

Gambar 1. Proses Pembuatan Tape 
Proses pembuatan tape Sucipto dimulai dengan mengupas kulit ubi kayu \pm 90 menit dan memotong \pm 30 menit dengan ukuran $\pm 9 \mathrm{~cm}$ atau berdasarkan ukuran kemasannya kemudian dibersihkan dengan air sampai bersih \pm 45 menit, setelah itu direbus dengan api sedang selama \pm dengan kipas angin selama 2 jam, selanjutnya disusun dalam kemasan dan ditaburkan ragi tape sampe selesai dalam jangka waktu 90 menit, disusun dalam kulkas setelah itu di diamkan selama \pm 2 hari sehingga terjadinya fermentasi Setelah itu sudah siap dipasarkan dengan masa expired date satu minggu.

\section{Jumlah Produksi}

Usaha tape memiliki ukuran tape yang diperjualbelikan yaitu dengan berat bersih 250 gr. Dalam satu kali produksi usaha ini bisa menghasilkan \pm 120 bungkus dan usaha tape melakukan proses produksi 8 kali dalam jangka waktu satu bulan dapat menghasilkan \pm 960 bungkus tape. Pola produksi tape memperoleh hasil yang sama setiap bulan yaitu \pm 960 tape karena memproduksi bahan baku setiap bulannya masih relative sama yaitu satu karung ubi kayu.

\section{Harga Jual}

Harga tape dijual sesuai dengan berat tape 250 gr. Tape ini hanya mengunakan bungkusan plastik dengan harga 6000/bungkus. Harga tape tidak mengalami perubahan walaupun harga bahan baku naik secara signifikan dan juga saat musim panas.

\section{Pemasaran Produk dan Biaya Produksi}

Hasil produksi tape dipasarkan di berbagai tempat dan sudah memiliki pelanggan tetap seperti Golden, Lotte, Indogrosir, Rumah makan KMB, dan Takadeli roti. Biaya produksi merupakan semua biaya yang dikeluarkan selama proses produksi pembuatan tape. Biaya yang dikeluarkan terdiri dari:

\section{Biaya Tetap (Fixed Cost)}

a. Biaya Listrik

Pemilik usaha membagi penggunaan biaya listrik untuk rumah tangga sebesar $90 \%$, sedangkan pemakaian untuk usaha $10 \%$. 30 menit. Setelah itu diangkat dan didinginkan

Biaya listrik untuk usaha tape mengunakan air yakni dengan mencelok pompa listrik air untuk mencuci ubi, untuk penerangan tempat usaha \pm 2 jam, mendinginkan ubi dengan kipas angin satu sampai dua jam, menggunakan kulkas untuk menyimpan tape selama kurang lebih 2 sampai 3 hari.

Biaya listrik perbulan secara keseluruhan yaitu sebesar Rp.2.000.000 jadi biaya listrik untuk usaha tape adalah sebesar $2.000 .000 \times 10$ $\%=200.000$ perbulan.

b. Biaya Penyusutan Alat

Biaya penyusutan alat yaitu nilai penyusutan selama peralatan digunakan. Nilai penyusutan alat per bulan untuk masing-masing alat dapat dilihat pada Tabel 2.

Tabel 2. Nilai Penyusutan Alat per Bulan

\begin{tabular}{llcc}
\hline No & Jenis Peralatan & $\begin{array}{c}\text { Jumlah } \\
\text { (Unit) }\end{array}$ & Nilai Penyusutan (Rp) \\
\hline 1 & Dandang Sedang & 1 & 366,67 \\
2 & Kompor & 1 & 133,33 \\
3 & Tabung gas & 1 & 833,32 \\
4 & Bascom & 2 & 666,68 \\
5 & Nyiru (tampah) & 3 & 3.000 \\
6 & Penjempit & 1 & 500 \\
& makanan & 1 & 333,33 \\
7 & Pisau & $\mathbf{1 0}$ & $\mathbf{5 . 6 6 8 , 3 3}$ \\
\hline \multicolumn{4}{l}{ Total } \\
\multicolumn{2}{l}{ Sumber: Diolah dari Data Primer, Tahun 2019}
\end{tabular}

Tabel 2 menunjukkan nilai penyusutan per bulan dari usaha tape Sucipto. Nilai penyusustan terbesar yaitu menggunakan dandang sedang yaitu sebesar Rp366,67. Perbulan kemudian diikuti penjepit makanan dan kompor sebesar Rp. 133,33. nilai penyusutan terkecil.

c. Biaya sewa tempat usaha

Usaha tape Sucipto ini mengeluarkan biaya untuk menyewa tempat untuk usaha yaitu sebesar Rp.500.000/bulan. Dimana biaya ini diambil dari salah satu pabrik tahu yang mana memproduksi dengan menggunakan bahan baku hanya 1 karung sama dengan tape.

Tabel 3. Biaya Tetap Usaha Tape Sucipto per Bulan

\begin{tabular}{clr}
\hline No & \multicolumn{1}{c}{ Jenis Biaya } & Jumlah (Rp) \\
\hline 1 & Biaya Listrik & 200.000 \\
2 & Biaya Penyusutan Alat & $5.668,33$ \\
3 & Biaya Sewa Tempat Usaha & 500.000 \\
\hline \multicolumn{3}{c}{ Total }
\end{tabular}




\section{Biaya Variabel (Variabel Cost)}

a. Biaya bahan baku

Bahan baku untuk pembuatan tape yang digunakan adalah ubi kayu. Setiap seminggu dua kali membeli ubi kayu di pasar Bersih Hati yang sudah menjadi langganan usaha tape. Bahan baku dibeli dua karung dalam seminggu.

Tabel 4. Biaya Bahan Baku Bulan September 2019

\begin{tabular}{cc}
\hline Bulan Produksi & September 2019 \\
\hline $\begin{array}{c}\text { Jumlah Pembelian } \\
\text { (perkarung) }\end{array}$ & 8 \\
$\begin{array}{c}\text { Harga Bahan Baku per } \\
\text { karung (Rp) }\end{array}$ & 220.000 \\
\hline Biaya (Rp) & $\mathbf{1 . 7 6 0 . 0 0 0}$ \\
\hline Sumber: Diolah dari Data Primer, Tahun 2019
\end{tabular}

\section{b. Biaya bahan penolong}

Bahan penolong yang digunakan dalam pembuatan tape adalah ragi tape. Dalam satu kali pembelian ragi tape bisa digunakan dua kali dalam seminggu. Harga ragi tape sebesar Rp. 20.000. maka biaya bahan penolong dalam pembuatan tape adalah sebesar Rp. 20.000.

Karena pembelian untuk bahan penolong dilakukan rutin setiap minggu sekali dengan harga dan jumlah yang sama maka jumlah biaya penolong yang keluarkan oleh usaha ini pada bulan September 2019 yaitu sebesar Rp.80.000.

c. Biaya bahan bakar

Bahan bakar yang digunakan sudah modern yaitu $3 \mathrm{~kg}$ gas lpg. Di beli satu kali untuk 2 kali pemakaian dalam seminggu. Harga gas lpg sebesar Rp.25.000 sehingga biaya bahan bakar dalam sehari sebesar Rp.12.500.

d. Biaya pengemasan.

Biaya pengemasan yang dikeluarkan untuk produk tape sucipto adalah biaya untuk membeli pastik dan print lebel produk sucipto. Usaha tape sucipto membeli plastik 120 lembar dengan harga Rp. 250 /Pc, Kemudian dikalikan dengan 8 kali produksi dalam jangka satu bulan sehingga total biaya yang dikeluarkan sebesar Rp.240.000/bulan. Foto copy lebel Sucipto 16 lembar biaya per lembar Rp. 250 jadi Rp.4.000 dan dikalikan dengan 8 kali produksi sehingga total biaya yang dikeluarkan sebesar Rp.32.000/bulan.

\begin{tabular}{lcccc}
\multicolumn{5}{l}{ Tabel 5. Biaya Pengemasan per Bulan } \\
\hline $\begin{array}{c}\text { Jenis } \\
\text { Bahan }\end{array}$ & Jumlah/lembar & Harga/PC & $\begin{array}{c}\text { Jumlah } \\
\text { produksi }\end{array}$ & Biaya \\
\hline Plastik & 120 & 250 & 8 & 240.000 \\
$\begin{array}{l}\text { Lebel } \\
\text { sucipto }\end{array}$ & 16 & 250 & 8 & 32.000 \\
\hline Total & & & \\
\hline Sumber: Diolah dari Data Primer, Tahun 2019 &
\end{tabular}

Tabel 5 menunjukkan bahwa dalam satu bulan produksi plastik untuk pengemasan dibeli sebanyak 8 kali dengaan biaya Rp.240.000 per bulan, serta lebel dibeli 8 kali dengan biaya Rp.32.000 per bulan. Jadi biaya yang dikeluarkan $240.000+32.000=272.000$. e. Biaya transportasi

Untuk memasarkan hasil produksi tape, pemilik usaha menggunakan kendaraan pribadi guna untuk menghemat biaya. Usaha dalam pabrik ini memiliki tiga produk yaitu Tahu, Tempe merupakan produk utama dengan produksi setiap hari sedangkan Tape hanya merupakan produk pelengkap dikarenakan produk ini hanya memproduksi 8 kali per bulan Sehingga biaya yang dikeluarkan sebesar Rp.6500 dalam satu kali pengantaran jadi, dalam satu bulan biaya yang dikeluarkan untuk biaya transportasi adalah $6500 \times 8=52.000$.

f. Biaya tenaga kerja

Dalam usaha tape ini memiliki tenaga kerja hanya satu orang yang berasal dari pemilik itu sendiri dan jangka waktu kerja \pm 8 jam perhari sehingga biaya untuk membayar tenaga kerja sebesar Rp.100.000/hari.

\begin{tabular}{clc}
\multicolumn{3}{c}{ Tabel 6. Biaya Variabel Bulan September 2019 } \\
\hline No & \multicolumn{1}{c}{ Jenis Biaya } & September 2019 \\
\hline 1 & Biaya Bahan Baku & 1.760 .000 \\
2 & Biaya Bahan Penolong & 80.000 \\
3 & Biaya Bahan Bakar & 100.000 \\
4 & Biaya Pengemasan & 272.000 \\
5 & Biaya Transportasi & 52.000 \\
6 & Biaya Tenaga Kerja & 800.000 \\
\hline & Total & $\mathbf{3 . 0 6 4 . 0 0 0}$ \\
\hline
\end{tabular}

Sumber: Diolah dari Data Primer, Tahun 2019 
Tabel 6 menunjukkan biaya variabel yang dikeluarkan bulan September 2019 biaya bahan baku yang harganya sama tiap satu kali produksi dalam satu minggu sebesar Rp.220.000.

\section{Biaya Total (Total Cost)}

Biaya total adalah semua biaya yang digunakan dalam usaha pembuatan tape meliputi total biaya tetap dan total biaya variabel. Besar biaya total yang dikeluarkan dapat dilihat pada tabel 7.

\begin{tabular}{cc}
\multicolumn{2}{c}{ Tabel 7. Biaya Total Usaha Tape Sucipto } \\
\hline Komponen Biaya & September 2019 \\
\hline Biaya Tetap & $705.668,33$ \\
Biaya Variabel & 3.064 .000 \\
\hline Total & $\mathbf{3 . 7 6 9 . 6 6 8 , 3 3}$ \\
\hline Sumber : Diolah dari Data Primer, Tahun 2019
\end{tabular}

Tabel 7 menunjukkan bahwa tidak adanya perbedaan besar biaya tetap pada bulan September 2019 dan begitupun dalam biaya variabel pada bulan September 2019.

\section{Penerimaan}

Penerimaan merupakan perkalian antara produksi tape yang dijual dengan harga tape. Penerimaan pada Bulan September 2019 ukuran tape berat bersih 250gram dengan harga Rp.6000 kali produksi 960 sehingga penerimaan adalah sebesar Rp. 5.760.000.

\section{Keuntungan}

Keuntungan yang diterima Usaha Tape Sucipto dalam satu bulan merupakan selisih dari penerimaan penjualan jumlah tape yang di produksi sesuai harga yang ada dan dikurangi dengan biaya-biaya yang dikeluarkan dalam proses produksi yaitu biaya tetap (fixed cost) dan biaya variabel (variabel cost).

Tabel 8. Keuntungan Usaha Tape Sucipto Bulan

\begin{tabular}{cr}
\multicolumn{2}{c}{ September 2019 } \\
\hline Komponen Biaya & September 2019 \\
\hline Penerimaan (Rp) & 5.760 .000 \\
Biaya Total (Rp) & $3.769 .668,33$ \\
\hline Total & $\mathbf{1 . 9 9 0 . 3 3 2 , 3 3}$ \\
\hline
\end{tabular}

Sumber: Diolah dari Data Primer, Tahun 2019
Tabel 8 menunjukkan bahwa keuntungan pada bulan September 2019 penerimaan yang diterima besar dan biaya total yang dikeluarkan lebih sedikit.

\section{Analisis Revenue Cost Ratio (R/C)}

Tingkat keuntungan Usaha Tape Sucipto dapat dihitung dengan menggunakan analisis Revenue Cost Ratio. Analisis ini merupakan perbandingan antara total penerimaan dan total biaya, dimana:

$\mathrm{R} / \mathrm{C}<1$, berarti usaha mengalami kerugian

$\mathrm{R} / \mathrm{C}=1$, berarti usaha tidak menguntun gkan dan

tidak merugikan

$\mathrm{R} / \mathrm{C}>1$, berarti usaha menerima keuntungan Nilai R/C Usaha Tape Sucipto pada bulan September 2019 sebesar Rp.1,52 menunjukkan angka $>1$, maka dapat disimpulkan bahwa usaha ini menguntungkan.

\section{KESIMPULAN DAN SARAN}

\section{Kesimpulan}

Keuntungan yang diterima CV Cipta Panca Persada dalam satu bulan dengan jumlah produksi serta biaya yang dikeluarkan dalam produk Tape Sucipto dapat menguntungkan pada bulan September 2019 sebesar Rp. $1.990 .332,33$.

Saran
Berdasarkan hasil penelitian
disarankan usaha ini perlu untuk terus
dikembangkan dengan Penambahan tenaga
kerja dan memperluas tempat pemasaran
produk sehingga konsumen lebih banyak dan
jumlah produksi bertambah dan lebih
menguntungankan lagi.

\section{DAFTAR PUSTAKA}

Boediono. 2016. Ekonomi Mikro. Edisi Kedua, Cetakan Ketigapuluh Satu. BPFE. Yogyakarta. 
Kumalasari, R. 2016. Analisis Keuntungan Pedagang Nasi Kuning, Studi Kasus Pedagang Nasi Kuning di Pasar Palaran Kecamatan Palaran Kota Samarinda. eJournal Administrasi Bisnis, 2016, 4 (4). Universitas Mulawarman.
Soeharni, 2006. Teori Mikroekonomi. CV Andi Offset. Yogyakarta.

Wardani, C. 2008. Analisis Usaha Pembuatan Tempe Kedelai Di Kabupaten Purworejo. Skripsi. Universitas Sebelas Maret.Surakarta. 